\title{
Assessment of the incidence rate of end-stage renal disease in patients with and without diabetes in Poland
}

\author{
Waldemar Wierzba ${ }^{1, A-F}$, Waldemar Karnafel ${ }^{1, A, C-D, F}$, Piotr Tyszko ${ }^{2, E}$, Krzysztof Kanecki, ${ }^{3, E-F}$, \\ Andrzej Śliwczyński ${ }^{1,4, B-C}$ \\ ${ }^{1}$ University of Humanities and Economics in Lodz, UHE Satellite Campus in Warsaw, Poland \\ ${ }^{2}$ Institute of Rural Health, Lublin, Poland \\ ${ }^{3}$ Medical University of Warsaw, Warsaw, Poland \\ ${ }^{4}$ National Health Fund, Central Office, Warsaw, Poland \\ A - Research concept and design, B - Collection and/or assembly of data, C - Data analysis and interpretation, \\ $D$ - Writing the article, E - Critical revision of the article, F - Final approval of article
}

Wierzba W, Karnafel W, Tyszko P, Kanecki K, Śliwczyński A Assessment of the incidence rate of end-stage renal disease in patients with and without diabetes in Poland. Ann Agric Environ Med. 2018; 25(3): 568-571. doi: 10.26444/aaem/89993

\begin{abstract}
Introduction. Several studies have suggested, that diabetes is very important factor of the risk of the chronic a renal disease. The paper aims to present a retrospective analysis of incidence of end-stage renal disease in subgroups of patients with and without diabetes in Poland.

Material and methods. For assessing this problem an electronic search was performed using Polish National Health Fund data base from 01.01.2011 until 31.12.2013 in general population and from 01.01.2012 until 31.12.2012 in 2 populations: with diabetes and without diabetes mellitus.

Results. The $43.70 \%$ patients with end-stage renal disease was diabetic. The incidence rate in 2012 was: $292.48 \pm 90.97$ diabetic men / 100,000 diabetic population; $203.10 \pm 90.97$ diabetic women / 100,000 diabetic population; $23.44 \pm 6.34$ non-diabetic men / 100,000 non-diabetic population; $17.88 \pm 6.33$ non-diabetic women / 100,000 non-diabetic population. Conclusions. The incidence rate of end-stage renal failure in diabetics was multiple times higher than the incidence rate in non-diabetics. The incidence rate of new ESRD cases in Poland estimated to be 36.17 per 100,000 of general populations in 2011, 35.28\% in 2012 and 30.46 per 100,000 of general populations in 2013. In 2012, the incidence rate of new ESRD cases in male diabetics was $292.48 \pm 90.97$ per 100,000 of diabetes men population, and in women diabetics $203.10 \pm 66.06$ per 100,000 of diabetes women population. In the same 2012 year, the incidence of new ESRD cases in men non-diabetics was $3.44 \pm 6.34$ per 100,000 of non-diabetes, and in women non-diabetes $17.58 \pm 6.33$ per 100,000 of non-diabetes women population.
\end{abstract}

\section{Key words}

diabetes mellitus, end-stage renal disease, incidence rate

\section{INTRODUCTION}

In 2010, end-stage renal disease (also called: ESRD or endstage renal failure) was the cause of renal replacement therapy for 2,618,000 people worldwide [1]. The exact number of patients with ESRD remains unknown - the disease is unpredictable, increasingly widespread, causes significant problems for the patients and generates enormous costs of medical treatment. ESRD is defined by Kidney Disease Improving Global Outcomes (KDIGO) as a glomerular filtration rate (eGFR) reduced below $15 \mathrm{ml} / \mathrm{min} / 1.73 \mathrm{~m}^{2}$ which lasts for 3 months or longer- and is referred to as stage 5 chronic kidney disease (G5) [2]. In their meta-analysis of 100 scientific reports from all around the world, which covered 6,908,440 people in total, Mill et al. show that chronic kidney disease (CKD) affects $13.4 \%$ of the world population [3]. Stage 1 of CKD (G1) is present in 3.5\% of the population, stage 2 (G2) in $3.9 \%$, stage 3 (G3) in $7.6 \%$, stage 4 (G4) in $0.4 \%$, and stage 5 (G5) in $0.1 \%$ [3].

Address for correspondence: Waldemar Wierzba, University of Humanities and Economics in Lodz., ul. Nowoursynowska 160/1, 02-776 Warszawa, Poland e-mail: wwierzba@post.pl

Received: 29.01.2018; accepted: 17.04.2018; first published: 25.04.2018
The main risk factors for CKD include diabetes, hypertension, and kidney diseases [4]. The glomerular filtration rate progressively decreases with aging [4]. CKD increases the risk of death and cardiovascular events [5], is the reason of frequent hospitalizations [1, 2], exacerbates cognitive impairment [6] and decreases the quality of life [7].

In this publication, the accumulated data was retrospectively analyzed for the incidence of new ESRD cases in patients with and without diabetes. The data on both subpopulations in Poland in 2012 was acquired from the National Health Fund database.

Objectives. The paper aims to present a retrospective analysis of incidence of end-stage renal disease in subgroups of patients with and without diabetes in Poland. Our retrospective analysis was constricted by inability to assess the causes of ESRD, the type of diabetes the patients had, and their metabolic control. The foreground ESRD diagnosis could have reduced the number of patients. In addition, the analysis could not determine if the diabetes was the cause of ESRD. Instead, the analysis showed cases of ESRD diagnosis in diabetics. 


\section{MATERIAL AND METHODS}

Health services in Poland are funded by National Health Fund (NHF - a third-party payer) under the Act of and the regulations of the Ministry of Health arising therefrom $[8,9$, 10]. The health services for diabetics in Poland are provided within the framework of both in-patient (hospitalization) and out-patient health care. The organization of those services is specified in the orders of the President of the National Health Fund $[11,12]$.

The data related to patient's personal identification number (PESEL) and to services on kidney failure marked according to ICD-10 (N18.0) [13] was extracted from the database on provided health services. The analysis was conducted for the years 2011-2013. In 2011, 2012, 2013, ESRD incidence rate for the general population were analyzed. In addition, in 2012, incidence rate of ESRD were analyzed for two subpopulations: diabetic and non-diabetic patients. Then, the data related to the patients with ICD-10 records with diabetes as a primary diagnosis was extracted: E10.X - Insulin-dependent diabetes mellitus, E11.X - Non-insulin-dependent diabetes mellitus, E12.X - Malnutrition-related diabetes mellitus, E13.X Other specified diabetes mellitus, E14.X - Unspecified diabetes mellitus. We also extracted the data on patients who reportedly filled their prescription for any of drugs from the group A10A.X (insulins) or A10B.X (oral anti-diabetic agents) and specialized diagnostic tests. All patients who received a refund for diabetes in 2012 were included. Date were obtained and prepared using the following tools: Structured Query Language and SAS software by SAS Institute. T-student test of independence were used. Differences were considered to be significant at the significance level of $95 \%(\mathrm{P}<0.05)$.

\section{RESULTS}

\section{Demographic data}

Table 1 shows the number of patients with ESRD in Poland in 2011, 2012 and 2013, broken down by gender (according to the National Health Fund database).

Table 1. Number of new ESRD cases in Poland in the years 2011-2013

\begin{tabular}{cccc}
\hline Year & Total Men and Women & Men & Women \\
\hline 2011 & 13,925 & $7625(54.76 \%)$ & $6300(45.24 \%)$ \\
\hline 2012 & 13,593 & $7287(53.61 \%)$ & $6306(46.39 \%)$ \\
\hline 2013 & 11,815 & $6289(53.23 \%)$ & $5526(46.77 \%)$ \\
\hline
\end{tabular}

In 2011, there were 13,925 new patients with ESRD in the NHF database, including 9,625 men and 6,300 women; in 2012 there were 13,593 new patients found, including 7,287 men and 6,306 women, and in 2013 there were 11,815 new patients $-6,289$ men and 5,526 women. In the observed period, men constituted $53.23 \%-54.76 \%$ of the patients, while women made up from $45.24 \%$ to $47 \%$.

According to data from the Central Statistical Office (GUS), in 2011 Poland covered a population of $38,501,000$ people, of whom 18,432 000 are men, 20067000 are women; in 2012 there were 38533789 people - 18651441 men and 19832 248 women; in 2013, there were 38793441 people - 18629 535 men and 20,163,906 women.

Table 2 shows the number of patients with ESRD in Poland in 2012 (according to the National Health Fund database), broken down by patients with and without recognized diabetes, taking into consideration gender, average age and standard deviation.

Table 2. Number of new ESRD cases in Poland in 2012 with information on diagnosed diabetes, sex and age of the patients

\begin{tabular}{cccccc}
\hline $\begin{array}{c}\text { ESRD } \\
\text { patients }\end{array}$ & Men & $\begin{array}{c}\text { Average age } \\
\pm \text { SD* }^{*}\end{array}$ & Women & $\begin{array}{c}\text { Average age } \\
\pm \mathrm{SD}^{*}\end{array}$ & $\begin{array}{c}\text { T-student } \\
\text { test }\end{array}$ \\
\hline $\begin{array}{c}\text { With } \\
\text { diabetes }\end{array}$ & $\begin{array}{c}3,027 \\
(50.96 \%)\end{array}$ & $67.73 \pm 17.69$ & $\begin{array}{c}2913 \\
(49,04 \%)\end{array}$ & $70,94 \pm 12,94$ & $\begin{array}{c}t=-7.957 ; \\
P<0.001\end{array}$ \\
\hline Without & 4260 & 62.76 & 3393 & 65,07 & $t=-5.799 ;$ \\
diabetes & $(55,66 \%)$ & \pm 17.18 & $(44,34 \%)$ & $\pm 17,47$ & $P<0.001$ \\
\hline $\begin{array}{c}T \text {-student } \\
\text { test of }\end{array}$ & $\begin{array}{c}t=12.019 ; \\
P<0.001\end{array}$ & & $t=14.952 ;$ & & \\
independence & & & $P<0.001$ & & \\
\hline
\end{tabular}

*Standard deviation

In the years 2011-2013, men made up from $53.23 \%$ to $54.76 \%$ of all ESRD patients. In 2012, men constituted $50.96 \%$ of all patients with both ESRD and recognized diabetes, while among patients without recognized diabetes they made up $55.66 \%$. In 2012, patients with recognized diabetes made up $43.70 \%$ of all $-41.57 \%$ and $46.19 \%$ for men and women, respectively.

The average age of patients with and without diabetes in both groups was significantly higher for women, $(\mathrm{P}<0.001)$. A comparison of the average age of men and women in both groups showed that the average age of both genders is significantly higher in the group of patients with recognized diabetes (diabetic versus without diabetic patients, at $\mathrm{P}<0.001)$.

The number of diabetic patients in Poland in 2012 amounted to 2,227,453 - 975,364 men and 1,252,089 women. On the other hand, the population of Poland without diabetes was $36,306,323$, including $17,676,027$ men and $18,625,254$ women.

The incidence was based on NHF database and estimated to be in the years 2011,2012, 2013. Table 3 shows the incidence of ESRD per 100,000 people in Poland in the years 2011-2013 (according to the National Health Fund), presented with a division based on gender.

Table 3. The incidence of ESRD per 100,000 people in Poland in the years 2011-2013

\begin{tabular}{cccc}
\hline Year & $\begin{array}{c}\text { End-stage renal failure } \\
\text { in both sexes }\end{array}$ & $\begin{array}{c}\text { End-stage renal failure } \\
\text { in men }\end{array}$ & $\begin{array}{c}\text { End-stage renal failure } \\
\text { in women }\end{array}$ \\
\hline 2011 & 36.17 & 41.73 & 31.49 \\
\hline 2012 & 35.28 & 39.07 & 31.73 \\
\hline 2013 & 30.46 & 33.76 & 27.41
\end{tabular}

The annual incidence of ESRD for both genders in Poland in the years 2011-2013 ranged from 33.76 to 41.37 per 100,000 . The annual incidence of ESRD in men in the years 2011-2013 ranged from 33.76 to 41.37 per 100,000. The annual incidence of ESRD in women in the years 2011-2013 ranged from 27.41 to 31.49 per 100,000 .

Comparison of the ESRD incidence in Poland, in patients with and without diabetes.

Table 4 compiles the percentage of ESRD incidence in Poland in people with and without recognized diabetes, broken down by gender and age, according to the NHF database from 2012. 
Table 4. The percentage of ESRD incidence in diabetic and non-diabetic patients in Poland in 2012, depending on the sex

\begin{tabular}{ccccc}
\hline \multirow{2}{*}{ Age ranges } & \multicolumn{2}{c}{ Patients with diabetes } & \multicolumn{2}{c}{ Patients without diabetes } \\
\cline { 2 - 5 } & Men & Women & Men & Women \\
\hline$<44$ & $4.31 \%$ & $4.43 \%$ & $16.24 \%$ & $13.43 \%$ \\
\hline $45-64$ & $16.59 \%$ & $22.25 \%$ & $34.45 \%$ & $27.70 \%$ \\
\hline $65-74$ & $29.42 \%$ & $28.53 \%$ & $20.61 \%$ & $23.44 \%$ \\
\hline$>75$ & $49.68 \%$ & $45.79 \%$ & $28.70 \%$ & $35.49 \%$ \\
\hline
\end{tabular}

In diabetics under 44 years of age, the ESRD incidence was observed in $4.31 \%$ men and $4.43 \%$ women, while among patients without diabetes in the same age group the percentages were $16.24 \%$ and $19.43 \%$ for men and women, respectively. For the age group of 45-64, the ESRD incidence in non-diabetic male patients was twice as high. The ESRD incidence in men diabetics aged 65 or more was $79.1 \%$, while in non-diabetic men it was $49.31 \%$. In women over 65 , however, this percentage was $74.32 \%$ for diabetics and $58.87 \%$ for non-diabetics.

Table 5 compiles the incidence of new ESRD cases in patients with and without diabetes per 100,000 people, after extracting the number of patients with recognized diabetes.

Table 5. The incidence rate of ESRD in patients with and without diabetes in Poland in 2012, calculated per 100,000 with diabetes and 100,000 population without diabetes, depending on the sex

\begin{tabular}{cccc}
\hline ESRD patients & Men & Women & $\begin{array}{c}\text { T-student test } \\
\text { of independence }\end{array}$ \\
\hline With diabetes & $292.48 \pm 90.97$ & $203.10 \pm 66.09$ & $\begin{array}{c}t=251.366 ; \\
p<0.001\end{array}$ \\
\hline Without diabetes & $23.44 \pm 6.34$ & $17.58 \pm 6.34$ & $\begin{array}{c}t=206.677 ; \\
p<0.001\end{array}$ \\
\hline $\begin{array}{c}T \text {-student test } \\
\text { of independence }\end{array}$ & $\begin{array}{c}t=932.967 ; \\
p<0.001\end{array}$ & $\begin{array}{c}t=883.620 ; \\
p<0.001\end{array}$ & \\
\hline
\end{tabular}

The ESRD incidence in men with recognized diabetes in Poland in 2012 was 12 times higher than in non-diabetics, with $\mathrm{P}<0.001$.

Similarly, the ESRD incidence in women with recognized diabetes in Poland in 2012 was 11.5 times higher than in non-diabetics, with $\mathrm{P}<0.001$.

In 2012, the incidence of end-stage renal disease in men was significantly higher in comparison to the incidence of end-stage renal disease in women, in both diabetic and nondiabetic patients, at $\mathrm{P}<0.001$.

Table 6 presents new ESRD cases in 2012 in people with recognized diabetes per 100,000 diabetics, and in people without recognized diabetes per 100,000 population after subtracting the number of diabetics, broken down by NHF regional branches and gender of the patients.

Particular attention was paid to, is the ESRD incidence in male diabetics higher than the average for the whole country in the following provinces: Wielkopolskie, Świętokrzyskie, Warmińsko-Mazurskie, Śląskie, Podkarpackie, Mazowieckie and Zachodnio-Pomorskie.

In female with diabetes, the incidence rate of ESRD higher than the average for the whole country was found in provinces: Warmińsko-Mazurskie, Wielkopolskie, Śląskie, Opolskie and Mazowieckie.
Table 6. The incidence of ESRD in patients with recognized diabetes (calculated per 100,000 with diabetes), and in patients without recognized diabetes (calculated per 100,000 people without diabetes) in Poland in 2012 , broken down by provinces and depending on the sex

\begin{tabular}{|c|c|c|c|c|c|}
\hline \multirow{2}{*}{\multicolumn{2}{|c|}{ Province }} & \multicolumn{2}{|c|}{$\begin{array}{c}\text { Patients } \\
\text { with diabetes }\end{array}$} & \multicolumn{2}{|c|}{$\begin{array}{c}\text { Patients } \\
\text { without diabetes }\end{array}$} \\
\hline & & Men & Women & Men & Women \\
\hline 1 & Dolnośląski & 299,12 & 166,69 & 25,40 & 17,73 \\
\hline 2 & Kujawsko-Pomorskie & 242,40 & 109,66 & 20,25 & 11,94 \\
\hline 3 & Lubelskie & 213,89 & 139,60 & 14,55 & 11,87 \\
\hline 4 & Lubuskie & 206,33 & 140,40 & 15,22 & 9,94 \\
\hline 5 & Łódzkie & 246,59 & 200,96 & 19,49 & 19,05 \\
\hline 6 & Małopolskie & 252,39 & 184,45 & 18,17 & 13,69 \\
\hline 7 & Mazowieckie & 306,38 & 252,93 & 30,16 & 18,85 \\
\hline 8 & Opolskie & 264,38 & 275,25 & 25,31 & 18,92 \\
\hline 9 & Podkarpackie & 354,29 & 272,02 & 25,08 & 17,39 \\
\hline 10 & Podlaskie & 208,77 & 119,12 & 13,74 & 10,14 \\
\hline & Pomorskie & 213,30 & 151,66 & 14,99 & 9,47 \\
\hline 12 & Śląskie & 364,91 & 279,66 & 26,44 & 19,98 \\
\hline & Świętokrzyskie & 229,42 & 172,28 & 26,70 & 20,14 \\
\hline 14 & Warmińsko-Mazurskie & 426,91 & 310,85 & 29,12 & 27,88 \\
\hline 15 & Wielkopolskie & 535,73 & 283,10 & 35,62 & 30,78 \\
\hline 16 & Zachodniopomorskie & 383,99 & 191,50 & 29,85 & 23,58 \\
\hline \multirow{2}{*}{\multicolumn{2}{|c|}{ Total POLAND }} & $\begin{array}{r}294,80 \\
+90,97\end{array}$ & $\begin{array}{r}203,10 \\
+66,90\end{array}$ & $\begin{array}{r}23,44 \\
+6,34\end{array}$ & $\begin{array}{r}17,58 \\
+6,34\end{array}$ \\
\hline & & $\pm 90,91$ & $\pm 00,90$ & $\pm 0,54$ & $\pm 0,34$ \\
\hline
\end{tabular}

The ESRD incidence rate higher than the average for the whole country was found in the following provinces: Wielkopolskie, Warmińsko-Mazurskie, ZachodnioPomorskie, Mazowieckie, Opolskie and Podkarpackie.

In women without diabetes, however, the ESRD incidence rate higher than the average for the whole country was found in the following provinces: Wielkopolskie, WarmińskoMazurskie, Zachodnio-Pomorskie and Świętokrzyskie.

This data must be interpreted with caution, for there is a possibility that, in example, the wards with more ESRD cases simply have better diagnostics. This problem may need further particular investigation.

\section{DISCUSSION}

According to our reports, the percentage of people with ESRD in the general population varies between $0.03 \%$ and $0.04 \%$, while Mill et al. in their meta-analysis claim it is $0.1 \%$ [3]. The conducted analysis was a retrospective study based on the National Health Fund data from the years 2011-2013, with included reports on hospitalizations and out-patient services in Poland.

The ESRD incidence in Poland is relatively wellcharacterized and described and, according to Polish authors, is similar to that in Western Europe countries [14, 15]. In the conducted study we analyzed new ESRD cases in people with and without recognized diabetes. The average age of diabetic patients was significantly higher than non-diabetic ones, regardless of gender. The average age of patients with diabetes was $67.73 \pm 12.69$ years for men and $65.07 \pm 17.47$ years for women. The average age of women, both diabetics and non-diabetics, was significantly higher than the average age of men, at $\mathrm{P}<0.001$. 
Many researchers emphasize that ESRD mainly affects people above 65 years of age $[3,16,17]$. In the study conducted by Mill et al., two thirds of the ESRD patients were women [3]. In our observation of all ESRD patients in the years 2011-2013, men constituted from 53.23 to $54.16 \%$ of their population. In 2012, men with ESRD and diagnosed with diabetes accounted for $50.91 \%$ of all patients with diabetes. However, among non-diabetic and ERDS patients, men accounted for $55.60 \%$ of all non-diabetic patients. Mill et al. [2] and Francisco et al. [18] reported that diabetics constituted over $30 \%$ of all ESRD patients $[3,18]$. According to our observations, diabetics of both genders made up $43.70 \%$ of all ESRD patients in $2012-41.57 \%$ of male patients and $46.19 \%$ of female patients suffered from both diseases at the same time.

Reports from the United States show that the percentage of patients with diabetes and ESRD was 45\% [19]. In the years 1995-2006 there was a large increase in the percentage of ESRD patients with diabetes [20]. In Japan, $40 \%$ of ESRD patients had diabetes [21]. In the United States there were 117,162 new ESRD cases in 2013, which is a rate of 36.3 per 100,000 of total population at the time [22]. In Poland, there were 13,925 people diagnosed with ESRD in 2011, which is a rate of 36.17 per 100,000 , and 13,593 people in 2012 , which is 35.28 per 100,000 . In 2013 , ESRD was diagnosed in 11,815 people, which is a rate of 30.46 per 100,000 . The rates of the incidence of new ESRD cases in Poland and in the United States are close.

In Japan, the incidence rate of ESRD for diabetics was 200 per 100,000 [21]. The incidence rate of ESRD for diabetics in the United States was 255.5 per 100,000 [23]. According to our observations based on National Health Fund database, the incidence rate of ESRD for men diabetics in Poland in 2012 was $292.48 \pm 90.97$ per 100,000 , and $203.10 \pm 66.06$ per 100,000 for women diabetics.

In the performed analysis the incidence rate of ESRD among the patients with recognized diabetes was calculated at $23.44 \pm 6.34$ per 100,000 patients without diabetes for men and $17.58 \pm 6.33$ per 100,000 patients without diabetes for women.

The incidence rate of ESRD in diabetics was multiple times higher than the incidence rate of ESRD in non-diabetics.

Our study is the first one to compare the incidence of end-stage renal disease in diabetic and non-diabetic patients in Poland.

\section{CONCLUSIONS}

1. The incidence rate of new ESRD cases in Poland estimated to be 36.17 per 100,000 of general populations in 2011, $35.28 \%$ in 2012 and 30.46 per 100,000 of general populations in 2013.

2. Men accounted for more than half of ESRD patients in the period from $01 / 01 / 2011$ to $31 / 12 / 2013$.

3. In 2012, 44\% ESRD patients were diabetes patients.

4. In 2012, the incidence rate of new ESRD cases in men diabetics was $292.48 \pm 90.97$ per 100,000 of diabetes man population, and in women diabetics $203.10 \pm 66.06$ per 100,000 of diabetes women population.

5. In the same 2012 year, the incidence of new ESRD cases in men non-diabetics was $3.44 \pm 6.34$ per 100,000 of nondiabetes, and in women non-diabetes $17.58 \pm 6.33$ per 100,000 of non-diabetes women population.
6. Diabetes significantly increases the risk of developing end-stage renal disease.

\section{REFERENCES}

1. Liyanage T, Ninomiya $\mathrm{T}$, Jha $\mathrm{V}$, et al. Worldwide access to treatment for end-stage kidney disease: a systematic review. Lancet. 2015; 385:19751982 .

2. Kdoqi Kdoqi. Chronic Kidney Disease Evaluation Classification. End Stratification 2012 http.//www.kidney.org/profesionals/kdoqi/ guidelines/commentaries.cfn

3. Hill NR, Fatoba ST, Oke JL, et al. Global Prevalence of Chronic Kidney Disease - A Systematic Review and Meta-Analysis. PLoS One. 2016; DOI.10.1371/journal.pone.0158765.

4. Gansevoort RT, Correa-Rotter R, Hemmelgarn BR, et al. Chronic kidney disease and cardiovascular risk: epidemiology, mechanisms, and prevention. Lancet. 2013; 382: 339-352.

5. Go AS, Chertow GM, Fan D et al. Chronic kidney disease and the risk of death, cardiovascular events, and hospitalization. N Engl J Med. 2004; 351:1296-1305.

6. Etgen T, Chonchol M, Förstl $\mathrm{H}$ et al. Chronic kidney disease and cognitive impairment: a systematic review and meta-analysis. Am J Nephrol. 2012; 35: 474-482.

7. Perlman RL, Finkelstein FO, Liu L i wsp. Quality of life in chronic kidney disease (CKD): a cross-sectional analysis in the Renal Research Institute-CKD study. Am J Kidney Dis. 2005; 45: 658-666.

8. Act of 27.08.2004 on health care services financed from public funds. (Journal of Laws 2008, no. 164, item 1027, as amended). Polish.

9. Regulation of the Minister of Health of 11 January 2010 amending the regulation on guaranteed benefits in the field of health programs (Journal of Laws 2010 No. 05, item 29, as amended). Polish.

10. Regulation of the Minister of Health of 2 March 2010 amending the regulation on guaranteed benefits in the field of hospital treatment (Journal of Laws of 2010, No. 30, item 157, as amended). Polish.

11. Order No. 101/2007/DGL of the President of the National Health Fund dated 5 November 2007 amending the Order on the adoption of "Detailed information materials on proceedings concerning the conclusion of healthcare contracts and the implementation and financing of healthcare contracts Type: hospital treatment”. Polish.

12. Order No. $36 / 2008 /$ DGL of the President of the National Health Fund of 19 June 2008 on defining the conditions for concluding and implementing contracts such as hospital treatment in the field of therapeutic health programs. Polish.

13. PESEL. http://www.msw.gov.pl/portal/pl/381/32/PESEL.html. Accessed Nov, 2017. Polish.

14. Chudek J, Wieczorkowska-Tobias K, Zejda J, et al. The prevalence of chronic kidney disease and its relation to socioeconomic conditions in an elderly Polish population: results from the national populationbased study PolSenior. Nephrol Dial Transplant. 2014; 29: 1073-1082.

15. Rutkowski B, Król E. Epidemiology of chronic kidney disease in central and eastern Europe. Blood Purif. 2008; 26:381-385.

16. O'Callaghan CA, Shine B, Lasserson DS. Chronic kidney disease: a large-scale population-based study of the effects of introducing the CKD-EPI formula for eGRF reporting. BMJ Open. 2011. DOI: 10.1136/ bmjopen-2011-000308.

17. Hommel K, Rasmussen S, Kamper AL, et al. Regional and social inequalities in chronic renal replacement therapy in Denmark. Nephrol Dial Transplant. 2010; 25: 2624-2632.

18. de Francisco AL, De la Cruz JJ, Cases A, et al. Prevalence of kidney insufficiency in primary care population in Spain: EUROCAMP study. Nefrologia. 2007; 27: 300-312.

19. National Kidney Fundation Kdoqi Clinical Practice Guidelines and Clinical Practice Recommendations for Diabetes and Chronic Kidney Diseases. Am J kid Dis. 2007; 49: 1-80.

20. US Renal Data System USRDS 2008 Annual Data Report Atlas of Chronic Kidney Disease And-Stage Renal Disease in the United States. Bethesda MB National Institute of Health, National Institute of Diabetes and Digestive and Kidney Disease 2008.

21. Iseki K. Chronic kidney disease in Japan. Intern Med. 2008; 47: 681-689.

22. United States Renal Data System 2015 ESROS Annual data report: Epidemiology of kidney disease in the United States National Institute of Health. National Institute of Diabetes and Digestive and Kidney Disease. Bethesda M. 2015.

23. Incidence of end a stage renal disease related to diabetes mellitus (ESRD-DH) per 100,000 diabetes population United States 1980-2008. http://www/cdc.gov/diabetes/statistics/esrd/fig7.htm 